\title{
Modelling Long Memory Volatility in Agricultural Commodity Futures Returns*
}

\author{
Chia-Lin Chang \\ Department of Applied Economics \\ Department of Finance \\ National Chung Hsing University \\ Taichung, Taiwan \\ Michael McAleer \\ Econometric Institute \\ Erasmus School of Economics \\ Erasmus University Rotterdam \\ and \\ Tinbergen Institute \\ The Netherlands \\ and \\ Department of Quantitative Economics \\ Complutense University of Madrid \\ and \\ Institute of Economic Research \\ Kyoto University, Japan

\section{Roengchai Tansuchat \\ Faculty of Economics \\ Maejo University \\ Chiang Mai, Thailand}

Revised: May 2012

* For financial support, the first author is most grateful to the National Science Council, Taiwan, the second author wishes to thank the Australian Research Council, National Science Council, Taiwan, and the Japan Society for the Promotion of Science, and the third author acknowledges the Faculty of Economics, Maejo University. 


\begin{abstract}
This paper estimates a long memory volatility model for 16 agricultural commodity futures returns from different futures markets, namely corn, oats, soybeans, soybean meal, soybean oil, wheat, live cattle, cattle feeder, pork, cocoa, coffee, cotton, orange juice, Kansas City wheat, rubber, and palm oil. The class of fractional GARCH models, namely the FIGARCH model of Baillie et al. (1996), FIEGARCH model of Bollerslev and Mikkelsen (1996), and FIAPARCH model of Tse (1998), are modelled and compared with the GARCH model of Bollerslev (1986), EGARCH model of Nelson (1991), and APARCH model of Ding et al. (1993). The estimated $d$ parameters, indicating long-term dependence, suggest that fractional integration is found in most of agricultural commodity futures returns series. In addition, the FIGARCH $(1, d, 1)$ and FIEGARCH $(1, d, 1)$ models are found to outperform their GARCH(1,1) and EGARCH(1,1) counterparts.
\end{abstract}

Keywords: Long memory, agricultural commodity futures, fractional integration, asymmetric, conditional volatility.

JEL: Q14, Q11, C22, C51. 


\section{Introduction}

Accurate modelling of volatility in asset returns is one of the major issues of concern in financial economics. Poon and Granger (2003) have mentioned that, even though volatility is not the same as risk, when it is interpreted as uncertainty it becomes a key input to many important financial applications, such as investment, portfolio construction, option pricing, hedging and risk management. Research on volatility models has focused on such different properties of the returns series as its time-varying conditional moments, volatility clustering, asymmetric patterns and long persistence, among others.

Derivative markets, particularly commodity futures markets, have become more sophisticated since the Chicago Broad of Trade commenced futures trading in 1848. The futures price depends on the flow of information around the world. Small changes in prices could have tremendous effects on trading results across futures markets. This distinction implies that the futures market is more volatile and has high risk. This feature is also particularly important in the agricultural commodity futures market, where factors such as drought, natural disaster, deforestation, and debt default can have a major impact on demand and supply of commodities, and hence on the present and futures prices of the commodity.

In modern time series modelling, following the seminal work of Engle (1982), a group of time series models named Autoregressive Conditional Heteroskedastity (ARCH), and later generalized by Bollerslev (1986) as Generalized Autoregressive Conditional Heteroskedastity (GARCH), has been used to model time-varying conditional volatility. The ARCH and GARCH models explain time series behaviour by allowing the conditional variance to evolve dynamically over time and to respond to previous price changes. These models consider nonlinearity in the conditional mean equation, and are also able to explain volatility clustering and volatility persistence. A considerable empirical literature in commodity cash and futures markets has used a variety of GARCH models to estimate expected price and returns volatility.

The GARCH model assumes that negative and positive shocks of equal magnitude have identical impacts on the conditional variance. In order to accommodate differential impacts on conditional variance between positive and negative shocks of equal magnitude, Glosten et al. (1992) proposed the asymmetric GARCH, or GJR model. As the positive and negative 
shocks on conditional volatility, called leverage effect, are asymmetric, Nelson (1991) proposed the Exponential GARCH (EGARCH) model.

In terms of volatility persistence, a GARCH model features an exponential decay in the autocorrelation of conditional variances. However, a shock in the volatility series seems to have very "long memory" and impacts on future volatility over a long horizon. Baillie et al. (2007) explained that the long memory refers to the presence of very slow hyperbolic decay in the autocorrelations and impulse response weights. Therefore, econometrically, the long memory is between the usual exponential rates of decay associated with the class of stationary and invertible ARMA models, and the alternative extreme of infinite persistence associated with integrated, unit root processes. Therefore, Baillie, Bollerslev and Mikkelsen (1996) (hereafter denoted BBM) proposed the FIGARCH( $(p, d, q)$ model, and Bollerslev and Mikkelsen (1996) proposed the $\operatorname{FIEGARCH}(p, d, q)$ model, where a full description of the properties of the process and the appropriate quasi-maximum likelihood estimation (QMLE) method can be found.

Several previous papers have observed and provided application of fractional integrated models in many fields, namely stock returns (Bollerslev and Mikkelsen (1996), Degiannakis (2004) and Ñiguez (2007), Lux and Kaizoji (2007), Kang and Yoon (2007), Jefferis and Thupayagale (2008), Ruiz and Veiga (2008)); exchange rate (Baillie et al. (1996), Davidson (2004), and Conrad and Lamla (2007)) and inflation rate (Baillie et al. (2002)). However, in the literature to date, there have been few applications of the fractionally integrated GARCH class models to commodity futures markets. Barkoulas et al. (1997) examined the fractional structure of commodities spot prices, namely aluminum, cocoa, coffee, copper, rice and rubber. They found that some commodity spot price time series display a fractional structure, and the fractional orders vary among these commodities because the processes involved in the price movements of each commodity varies.

Crato and Ray (2000) investigated long-term memory in the returns and volatility of commodity futures market, namely five currencies, twelve agricultural commodities, three metals and heating oil, and five currencies futures markets. They found that commodity futures volatilities are typically more persistent than currency futures volatilities. However, they do not explicitly estimate the FIGARCH model. Jin and Frechette (2004) examined the 
presence of fractional integration in the volatility of fourteen agricultural futures prices series using data from 1970 to 2000 . The results show that the volatility series exhibit strong longterm dependence, which is an indicator of fractional integration. In addition, FIGARCH(1,d,1) performs significantly better than a traditional volatility model, GARCH(1,1), in modelling agricultural price volatility.

Baillie et al. (2007) examined long memory in volatility properties of both daily and highfrequency intraday futures returns for six important commodities. They found that the volatility processes were found to be accurately described by FIGARCH models, with statistically significant long memory parameter estimates.

Recently, Hyun-Joung (2008) explored a long memory conditional volatility model on international grain markets, namely wheat, corn and soybeans, and compared the performance of the models in capturing dependence of the price volatility, and also emphasized suitability of the student- $t$ density intended to account for non-normal, fat-tailed properties of the data. The empirical results showed that grain cash price volatilities exhibit long memory and that the memory is adequately modelled by a fractionally integrated process and implemented by FIGARCH models. In addition, the suitability of the FIGARCH models is under the student- $t$ distribution and the competitiveness of the parsimonious FIGARCH(1,d,0) model. Therefore, it is desirable to use long memory conditional variance models for analysis of grain price volatility dynamics.

The fractionally integrated multivariate conditional volatility model of Brunetti and Gilbert (2000) applied the univariate volatility (FIGARCH) model to multivariate GARCH models by estimating and testing cointegrated bivariate FIGARCH models using NYMEX and IPE crude oil markets. They found a common order of fractional integration for the two volatility process, and confirmed that they are fractionally cointegrated. An estimated error correction FIGARCH model indicated that the predominant adjustment is the IPE toward NYMEX.

Coakley et al. (2008) explored the relationship between basis long memory and hedging effectiveness measures with error-correction and the multivariate GARCH (FIEC-BEKK) model, employing spot daily data and their corresponding futures contracts 1995-2005 for five commodities, namely soybeans, cocoa, heating oil, gold and live cattle. The results 
presented a long memory component that should theoretically affect hedging effectiveness. Recently, Sephton (2009) reexamined the findings in Jin and Frechette (2004) and used the same dataset to provide evidence of fractional integration using the FIGARCH and FIAPGARCH models. The updated empirical results generally confirm the presence of long memory in conditional variances, with some commodity futures displaying significant leverage effects.

The aims of the paper are to analyse agricultural commodity futures returns using several conditional volatility models, namely GARCH, EGARCH and APARCH, and fractionally integrated conditional volatility models, namely FIGARCH, FIEGARCH and FIAPARCH, as an extension of existing results. The paper differs from existing studies in three respects. First, due to changes in the financial and economic environment, such as the 2008-09 global financial crisis, an increasing number of market participants, product yield uncertainty, changes in the demand and supply position of agricultural commodities and growing international competition, agricultural commodity futures markets have matured considerably over the last decade. An extension in the sample period from 2000 to 2009, giving an additional 2,500 observations, is intended to allow a suitable analysis of these issues.

Second, none of the preceding papers has used a variety of fractionally integrated GARCH models for purposes of comparison with conventional GARCH models. This paper estimates five fractionally integrated GARCH models, namely FIGARCH of Baillie et al. (1996), FIGARCH of Chung (1999), FIEGARCH of BBM (1996), FIAPGARCH of Ding, Granger and Engle (1993), and FIAPGACH of Tse (1998), and compares the estimates with conventional GARCH models. Four important agricultural commodity futures are considered, namely cotton, orange juice, and two tropical rain plants in palm oil and rubber. These agricultural commodity futures have not yet been examined using long memory models. The empirical findings in this paper should make a useful contribution to all agents involved in the sale, purchase and distribution of agricultural commodities, including related industries.

This empirical analysis given below indicates that, on the basis of the EGARCH and APGARCH models, most agricultural commodity futures returns have asymmetric effects, with only a few displaying leverage effects. Thus, it would appear that the GARCH model is not appropriate for analyzing agricultural commodity futures returns. Moreover, evidence of 
long memory is found for each agricultural commodity futures returns using both FIGARCH and FIAPGARCH of the BBM and Chung specifications. In addition, asymmetric and leverage effects are found for some agricultural commodities using FIEGARCH and FIAPGARCH, which suggests that the FIGARCH model is not appropriate for modelling agricultural commodity futures returns.

The remainder of the paper is organized as follows. Section 2 discusses the methodological approach used in the paper. Section 3 describes the commodity futures prices time series. Section 4 presents the results from empirical modelling, and Section 5 provides some concluding comments.

\section{Econometric Models}

\subsection{Univariate Conditional Volatility Models}

This section presents the volatility models in commodity futures returns, namely the GARCH model of Bollerslev (1986), EGARCH model of Nelson (1991) and APARCH model of Ding et al. (1993), and fractionally integrated conditional volatility models, namely FIGARCH model of Baillie et al. (1996), FIEGACH model of Bollerslev and Mikkelsen (1996), and FIAPARCH model of Tse (1998).

Following Engle (1982), consider the time series, $y_{t}=E_{t-1}\left(y_{t}\right)+\varepsilon_{t}$, where $E_{t-1}\left(y_{t}\right)$ is the conditional expectation of $y_{t}$ at time $t-1$ and $\varepsilon_{t}$ is the associated error. The generalized autoregressive conditional heteroskedastity (GARCH) model of Bollerslev (1986) is given as follows:

$$
\begin{gathered}
\varepsilon_{t}=\sqrt{h_{t}} \eta_{t} \quad, \quad \eta_{t} \square N(0,1) \\
h_{t}=\omega+\sum_{j=1}^{p} \alpha_{j} \varepsilon_{t-j}^{2}+\sum_{j=1}^{q} \beta_{j} h_{t-j}=\omega+\alpha(L) \varepsilon_{t}^{2}+\beta(L) \sigma_{t}^{2}
\end{gathered}
$$

where $\omega>0, \alpha_{j} \geq 0$ and $\beta_{j} \geq 0$ are sufficient conditions to ensure that the conditional variance $h_{t}>0, \quad L \quad$ is the lag operator, $\quad \alpha(L)=\alpha_{1} L+\alpha_{2} L^{2}+\ldots+\alpha_{p} L^{p} \quad$ and $\beta(L)=\beta_{1} L+\beta_{2} L^{2}+\ldots+\beta_{q} L^{q}$. In (2) the parameter $\alpha_{j}$ represents the ARCH effect, or the short-run persistence of shocks to returns, $\beta_{j}$ represents the GARCH effects, and $\left(\alpha_{j}+\beta_{j}\right)$ 
measures the persistence of the contribution of shocks to return $i$ to long-run persistence. If the roots of $[1-\alpha(L)-\beta(L)]$ and $[1-\beta(L)]$ lie outside the unit circle, then $\left\{\varepsilon_{t}^{2}\right\}$ exhibits stability and covariance stationarity. The volatility shocks decay at a geometric rate.

Equation (2) assumes that the conditional variance is a function of the magnitudes of the lagged residuals and not their sign, such that a positive shock $\left(\varepsilon_{t}>0\right)$ has the same impact on the conditional variance as a negative shock $\left(\varepsilon_{t}<0\right)$ of equal magnitude. In order to accommodate differential impacts on the conditional variance of positive and negative shocks, Glosten et al. (1992) proposed the asymmetric GARCH, or GJR model, as given by

$$
h_{t}=\omega+\sum_{j=1}^{r}\left(\alpha_{j}+\gamma_{j} I\left(\eta_{t-j}\right)\right) \varepsilon_{t-j}^{2}+\sum_{j=1}^{s} \beta_{j} h_{t-j}
$$

where

$$
I_{i t}= \begin{cases}0, & \varepsilon_{i t} \geq 0 \\ 1, & \varepsilon_{i t}<0\end{cases}
$$

is an indicator function to differentiate between positive and negative shocks. Bollerslev (1986) showed the necessary and sufficient condition for the second-order stationarity of GARCH is $\sum_{j=1}^{r} \alpha_{j}+\sum_{j=1}^{s} \beta_{j}<1$. For the GARCH(1,1) model, Nelson (1990) obtained the logmoment condition for the strict stationary and ergodicity as $E\left(\log \left(\alpha_{1} \eta_{t}^{2}\right)+\beta_{1}\right)<0$, which is important in deriving the statistical properties of the QMLE.

In an alternative model that accommodates asymmetry between positive and negative shocks, and possibly also leverage, Nelson (1991) proposed the Exponential GARCH (EGARCH) model, interpreting as ARMA-type models for the logarithm of the conditional variance, namely:

$$
\log h_{t}=\omega+\sum_{i=1}^{p} \alpha_{i}\left|\eta_{t-i}\right|+\sum_{i=1}^{p} \gamma_{i} \eta_{t-i}+\sum_{j=1}^{q} \beta_{j} \log h_{t-j} .
$$

In (4), $\left|\eta_{t-i}\right|$ and $\eta_{t-i}$ capture the size and sign effects, respectively, of the standardized shocks. Unlike the GARCH model, EGARCH in (4) uses the standardized residual rather than the unconditional shocks. As EGARCH also uses the logarithms of conditional volatility, there are no restrictions on the parameters in (4). As the standardized shocks have 
finite moments, the moment conditional of (4) are straightforward. The distinctions between EGARCH and the previous two GARCH models are discussed in McAleer (2005) and McAleer et al. (2007)

Alternatively, Bollerslev and Mikkelsen (1996) proposed expressing the EGARCH model as follows:

$$
\ln \left(\sigma_{t}^{2}\right)=\omega+[1-\beta(L)]^{-1}[1+\alpha(L)] g\left(z_{t-1}\right) .
$$

The value of $g\left(z_{t}\right)$ depends on several elements. Following Nelson (1991), in order to accommodate the asymmetric relation between returns and volatility changes, the value of $g\left(z_{t}\right)$ must be a function of both the magnitude and sign of $z_{t}$, which yields the function $g\left(z_{t}\right)$ expressed as

$$
g\left(z_{t}\right)=\underbrace{\gamma_{1} z_{t}}_{\text {sign effect }}+\underbrace{\gamma_{2}\left[\left|z_{t}\right|-E\left|z_{t}\right|\right]}_{\text {magnitude effect }} .
$$

The parameter $\gamma_{1}$ captures the leverage effect. If $\gamma_{1}<0$, the futures conditional variances will increase proportionally more as a result of a negative shock than for a positive shock of the same absolute magnitude.

Ding, Granger and Engle (1993) proposed an asymmetric power GARCH (APARCH) model, whereby the power of the standard deviation, $\sigma_{t}^{\delta}$, where $\delta>0$, is a parameter to be estimated. The $\operatorname{APARCH}(p, q)$ is definded as:

$$
\sigma_{t}^{\delta}=\omega+\sum_{j=1}^{p} \alpha_{j}\left(\left|\varepsilon_{t-i}\right|-\gamma_{i} \varepsilon_{t-i}\right)^{\delta}+\sum_{j=1}^{q} \beta_{j} \sigma_{t-j}^{\delta}
$$

and $-1<\gamma_{i}<1,(i=1, \ldots, q)$. This model nests at least seven ARCH-type models, namely the ARCH model of Engle (1982), GARCH model of Bollerslev (1986), Taylor/Schwert GARCH in standard deviation of Taylor (1986) and Schwert (1990), GJR model of Glosten et al. (1993), TARCH of Zakoian (1994), NARCH of Higgins and Bera (1992), and logARCH of Geweke (1986) and Pantula (1986). Following Ding et al. (1993), if $\omega>0$ and $\sum_{i=1}^{p} \alpha_{i} E\left(|z|-\gamma_{i} z\right)^{\delta}+\sum_{j=1}^{q} \beta_{j}<1$, a stationary solution for equation (7) exists and is given by 


$$
E\left(\sigma_{t}^{\delta}\right)=\frac{\alpha_{0}}{1-\sum_{i=1}^{p} \alpha_{i}\left(|z|-\gamma_{i} z\right)^{\delta}+\sum_{j=1}^{q} \beta_{j}}
$$

In order to estimate the parameters of model (1)-(7), maximum likelihood estimation is used with a joint normal distribution of $\eta_{t}$. However, when the process for $\eta_{t}$ does not follow a normal distribution, or when the conditional distribution is not known, the solution to maximizing the likelihood function is the quasi-MLE (QMLE) approach.

\subsection{Univariate fractional integrated conditional volatility models}

The long memory property can be defined through the properties of the autocorrelation function, which is defined as $\rho_{k}=\operatorname{cov}\left(x_{t}, x_{t-1}\right) / \operatorname{var}\left(x_{t}\right)$ for integer lag $k$. A covariance stationary time series process is expected to have autocorrelations such that $\lim _{k \rightarrow \infty} \rho_{k}=0$. Most of the well-known class of stationary and invertible time series processes have autocorrelations that decay at the relatively fast exponential rate, so that $\rho_{k} \approx|m|^{k}$, where $|m|<1$, and this property is true, for example, for the well-known stationary and invertible $\operatorname{ARMA}(p, q)$ process. For long memory processes, the autocorrelations decay at an hyperbolic rate which is consistent with $\rho_{k} \approx c_{1} k^{2 d-1}$ as $k$ increases without limit, where $c_{1}$ is a constant and $d$ is the long memory parameter.

In applications, it often occurs that the estimated sum of parameters $\alpha_{1}$ and $\beta_{1}$ in $\operatorname{GARCH}(1,1)$ is close to unity, that is $\sum_{i=1}^{p} \alpha_{i}+\sum_{j=1}^{q} \beta_{j} \approx 1$, or for $\operatorname{GARCH}(p, q)$, the process exhibits strong persistence. If $\sum_{i=1}^{p} \alpha_{i}+\sum_{j=1}^{q} \beta_{j}<1$, the process $\left(\varepsilon_{t}\right)$ is second-order stationary, and a shock to the conditional variance $h_{t}$ has a decaying impact on $h_{t+h}$, when $h$ increases, and is asymptotically negligible. However, if $\sum_{i=1}^{p} \alpha_{i}+\sum_{j=1}^{q} \beta_{j} \geq 1$, the effect on $h_{t+h}$ does not die out asymptotically. 
This property is called persistence. Under the restriction $\sum_{i=1}^{p} \alpha_{i}+\sum_{j=1}^{q} \beta_{j}=1$, Engle and Bollerslev (1986) developed the integrated GARCH (IGARCH) model, meaning that current information remains of importance when forecasting the volatility for all horizons:

$$
\phi(L)(1-L) \varepsilon_{t}^{2}=\omega+[1-\beta(L)] v_{t}
$$

where $v_{t}=\varepsilon_{t}^{2}-\sigma_{t}^{2}$ is the "innovation" in the conditional variance process or martingale difference process with respect to $\sigma_{t}^{2}$ or $h_{t}$, and has mean 0 and no serial correlation, $\phi(L)=[1-\alpha(L)-\beta(L)](1-L)^{-1}$, and all the roots of $\phi(L)$ and $[1-\beta(L)]$ lie outside the unit circle.

However, volatility tends to change quite slowly over time and, as shown in Ding et al. (1993), the effects of a shock can take a considerable time to decay. Therefore, the distinction between $I(0)$ and $I(1)$ processes seems to be too restrictive. Indeed, the propagation of shock in an $I(0)$ process shocks dies out at an exponential rate (so that it only captures short memory) and, for an $I(1)$ process, the persistence of shocks is infinite and there is no mean reversion, whereas $0<d<1$ shocks die out at a slow hyperbolic rate. Baillie et al. (1996) introduced the fractionally integrated GARCH (FIGARCH) model in order to capture the long memory effect in volatility, allows a hyperbolic decay of the coefficient, $\beta_{j}$, which is positive, summable, and satisfies the unit root condition. This model mimics the ARFIMA framework of the conditional mean equation.

The FIGARCH$(p, d, q)$ process is defined as:

$$
\phi(L)(1-L)^{d} \varepsilon_{t}^{2}=\omega+\{1-\beta(L)\} v_{t},
$$

where all the roots of $\phi(L)$ and $\{1-\beta(L)\}$ lie outside the unit circle. Analogously to (9), the FIGARCH process can be represented as:

$$
h_{t}=\underbrace{\omega[1-\beta(L)]^{-1}}_{\omega^{*}}+\underbrace{\left\{1-[1-\beta(L)]^{-1} \phi(L)(1-L)^{d}\right\}}_{\lambda(L)} \varepsilon_{t}^{2},
$$

or $h_{t}=\omega^{*}+\lambda_{i}\left(L^{i}\right) \varepsilon_{t}^{2}=\omega^{*}+\lambda(L) \varepsilon_{t}^{2}$, when $0<d<1 . \quad(1-L)^{d}$, where $0<d<1$, is the fractional differencing operator, and its value depends on the decay rate of a shock to conditional volatility. It is also most conveniently expressed in term of the hypergeometric 
function:

$$
\begin{gathered}
(1-L)^{d}=\sum_{k=0}^{\infty} \frac{\Gamma(d+1)}{\Gamma(k+1) \Gamma(d-k+1)} L^{k} \\
\text { or } \quad(1-L)^{d}=\sum_{k=0}^{\infty}\left(\begin{array}{l}
d \\
k
\end{array}\right)(-L)^{k}=1-d L-\frac{1}{2} d(1-d) L^{2}-\frac{1}{6} d(1-d)(2-d) L^{3}-\ldots
\end{gathered}
$$

It is easy to show that $\omega>0, \beta_{1}-d \leq \phi_{1} \leq \frac{2-d}{2}$ and $d\left(\phi_{1}-\frac{1-d}{2}\right) \leq \beta_{1}\left(\phi_{1}-\beta_{1}+d\right)$ are sufficient to ensure that the conditional variance of the $\operatorname{FIGARCH}(1, d, 1)$ is positive almost surely for all $t$. FIGARCH nests the GARCH model when $d=0$, and the IGARCH model when $d=1$. Approximate maximum likelihood estimates of the parameters of the FIGARCH $(p, d, q)$ process in (9) can be obtained by QMLE.

Chung (1999) argued that the method of parameterization of the FIGARCH model of Baillie et al. (1996) may have a specification problem, and underscores some drawbacks in the BBM model. There may be a structural problem in the BBM specification in parallel with the ARFIMA framework of the conditional mean equation, thereby leading to difficult interpretations of the estimated parameters. Indeed, the fractional differencing operator applies to the constant term in the mean equation (ARFIMA), while it does not do so in the variance equation (FIGARCH). Therefore, Chung (1999) redefines the FIGARCH model as:

$$
\phi(L)(1-L)^{d}\left(\varepsilon_{t}^{2}-\sigma^{2}\right)=[1-\beta(L)]\left(\varepsilon_{t}^{2}-\sigma_{t}^{2}\right),
$$

where $\sigma^{2}$ is the unconditional variance of $\varepsilon_{t}$. If we retain the same definition of $\lambda(L)$ as in (13), we can formulate the conditional variance as:

$$
\begin{gathered}
h_{t}=\sigma^{2}+\left\{1-[1-\beta(L)]^{-1} \phi(L)(1-L)^{d}\right\}\left(\varepsilon_{t}^{2}-\sigma^{2}\right) \\
\text { or } \quad h_{t}=\sigma^{2}+\lambda(L)\left(\varepsilon_{t}^{2}-\sigma^{2}\right) .
\end{gathered}
$$

In order to accommodate asymmetries between positive and negative shocks, called the leverage effect, Bollerslev and Mikkelsen (1996) extend the FIGARCH process to FIEGARCH, to correspond with Nelson's (1991) Exponential GARCH model to allow for asymmetry. The $\operatorname{FIEGARCH}(p, d, q)$ model is given as

$$
\ln \left(h_{t}\right)=\omega+\phi(L)^{-1}(1-L)^{-d}[1+\alpha(L)] g\left(z_{t-1}\right),
$$


where $g\left(z_{t}\right)=\theta z_{t}+\gamma\left[\left|z_{t}\right|-E\left|z_{t}\right|\right]$, the first term $\left(\theta z_{t}\right)$ is the sign effect, and the second term $\left(\gamma\left[\left|z_{t}\right|-E\left|z_{t}\right|\right]\right)$ is the magnitude effect. All the roots of $\phi(L)$ and $\lambda(L)$ are an autoregressive polynomial and a moving average polynomial in the lag operator $L$ and lie outside the unit circle, and both polynomials do not have a common root. When $d=0$, the $\operatorname{FIEGARCH}(p, d, q)$ process reduces to EGARCH of Nelson (1991), and when $d=1$, the process becomes integrated EGARCH (IEGARCH). Bollerslev and Mikkelson (1996) presented evidence on the efficiency of QMLE applied to estimate the parameters of the FIEGARCH process.

Tse (1998) proposed a model which combines the fractionally integrated GARCH formulation of Baillie et al. (1996) with the asymmetric power ARCH specification of Ding, Granger and Engle (1993) (see Ling and McAleer (2002) for the theoretical properties of the model). This model increases the flexibility of the conditional variance specification by allowing: (a) an asymmetric response of volatility to positive and negative shocks; (b) the data to determine that power of returns for which the predictable structure in the volatility pattern is the strongest; and (c) long range volatility dependence. The $\operatorname{FIAPARCH}(p, d, q)$ model can be written as:

$$
\sigma_{t}^{\delta}=\omega+\left\{1-[1-\beta(L)]^{-1} \phi(L)(1-L)^{d}\right\}\left(\left|\varepsilon_{t}\right|-\gamma \varepsilon_{t}\right)^{\delta},
$$

where $\gamma$ is the leverage coefficient, and $\delta$ is the parameter for the power term that takes (finite) positive values. When $d=0$, the $\operatorname{FIAPARCH}(p, d, q)$ process reduces to APARCH of Ding et al. (1993). When $\gamma=0$ and $\delta=2$, the process in (13) reduces to the FIGARCH $(p, d, q)$ specification, which includes Bollerslev's (1986) model when $d=0$, and the integrated specification when $d=1$, as special cases.

\section{Data}

The data are daily synchronous closing futures prices of agricultural futures on different major US commodity futures markets, specifically, the Chicago Broad of Trade (CBOT) for corn, oats, soybeans, soybean meal, soybean oil and wheat; the Chicago Mercantile Exchange (CME) for cattle feeder, live cattle and pork, the New York Broad of Trade (NYBOT) for cocoa, cotton, coffee and orange juice, and Kansas City Broad of Trade (KCBOT) for wheat. 
The 7,889 price observations from 4 January 1979 to 16 April 2009 are obtained from the DataStream database service.

This paper also focuses on two important commodity futures prices of tropical rain plants, namely rubber (RSS3), trading on the Tokyo Stock Exchange (TOCOM), which 5,012 price observations started from 23 January 1990 to 8 April 2009, and palm oil, trading on the Malaysia Derivatives Exchange (MDEX), which 7,425 price observations started from 23 October 1980 to 8 April 2009. These two commodity futures prices are expressed in local currencies and are obtained from Reuters. The returns of agricultural futures prices $i$ of commodity $j$ at time $t$ in a continuous compound basis are calculated as $r_{i j, t}=\log \left(P_{i j, t} / P_{i j, t-1}\right)$, where $P_{i j, t}$ and $P_{i j, t-1}$ are the closing prices of the agricultural futures prices $i$ of commodity $j$ for day $t$ and $t-1$, respectively.

The descriptive statistics for the agricultural commodity futures returns series are summarized in Table 1 . The sample mean is quite small, but the corresponding variance of returns is much higher. Surprisingly, 4 of 16 return series have negative average returns, namely cocoa, coffee, cotton and orange juice. The normal distribution has a skewness statistic equal to zero and a kurtosis statistic of 3, but these agricultural commodity futures returns have high kurtosis, suggesting the presence of fat tails, and 9 of 16 return series have negative skewness, signifying the series have a longer left tail (extreme loss) than right tail (extreme gain). The Jarque-Bera (J-B) test Lagrange multiplier statistics of the agricultural commodity futures return series are statistically significant, thereby signifying that the distributions for these returns are not normal, which may be due partly to the presence of extreme observations.

\section{[Insert Table 1 here]}

Figures 1-2 present the plots of synchronous agricultural commodity futures returns. These indicate volatility clustering, or periods of high volatility followed by periods of tranquility, such that agricultural commodity futures returns fluctuate in a range smaller than under the normal distribution. However, there are some circumstances where agricultural commodity futures returns oscillate in a much wider scale that is permitted by a normal distribution. 


\section{[Insert Figures 1-2 here]}

The unit root test for all commodity futures returns are summarized in Table 2. All unit root tests are conducted with EViews 6 econometric software package. The Augmented DickeyFuller (ADF) and Phillips-Perron (PP) tests were used to explore the existence of unit roots in the individual returns series. The ADF test accommodates serial correlation by specifying explicitly the structure of serial correlation in the error, but the PP test allows fairly mild assumptions that do not assume a specific type of serial correlation and heteroskedastity in the disturbances, and can have higher power than the ADF test under a wide range of circumstances. These results are checked by also performing the KPSS test. The null hypothesis of the ADF and PP tests is that the series have a unit root, while the null hypothesis of the KPSS test is that the series are stationary.

In Table 2, based on the ADF and PP test results, the large negative values in all cases indicate rejection of the null hypothesis at the 1\% level. In addition, based on the KPSS test, the results indicate that the null hypothesis is not rejected at the $1 \%$ level, such that all agricultural commodity futures returns series are stationary.

\section{[Insert Table 2 here]}

\section{Empirical Results}

This section investigates a relevant framework of the conditional variance model through comparison among different specifications. The univariate conditional volatility model, namely the GARCH model of Bollerslev (1986), EGARCH model of Nelson (1991) and APARCH model of Ding et al. (1993), and fractionally integrated class of models, namely the FIGARCH model of Baillie et al. (1996), FIGARCH model of Chung (1999), FIEGARCH model of Bollerslev and Mikkelsen (1996), FIAPARCH model of Tse (1998), and FIAPARCH model of Chung (1996) with Gaussian errors, are estimated by QMLE, which allows for asymptotically valid inferences when the standardized innovations are not normally distributed. Corresponding estimates are obtained using the BFGS algorithm. The computations are performed using the Ox/G@RCH 4.2 econometrics software package of Laurent and Peters (2006). 


\section{[Insert Table 3 here]}

The univariate estimates of the conditional volatilities, $\operatorname{GARCH}(1,1), \operatorname{EGARCH}(1,1)$ and APARCH(1,1) of each agricultural commodity futures returns are given in Tables 3 to 5 . Their respective estimates and robust $t$-ratios of each parameters are presented including information criteria, namely AIC and SIC. Table 3 presents the estimates of the GARCH $(1,1)$ models from equation (1) and (2) for commodity futures returns. The coefficients in the conditional variance equation are all significant, but with corn, cotton and wheat (Kansas City wheat), only in the long run. The details of the univariate estimates relating to the structural properties, namely the second moment and log-moment conditions, based on agricultural commodity futures returns, are available from the authors upon request.

\section{[Insert Table 4 here]}

Table 4 shows the estimates of the $\operatorname{EGARCH}(1,1)$ models from equations (5) and (6) for commodity futures returns. Most commodity futures returns show that the estimates of $\gamma_{2}$ are statistically significant, meaning that these returns have an asymmetric effect of negative and positive shocks on the conditional variance. Surprisingly, only for cattlef (cattle feeder) and pork are both estimates of $\gamma_{1}$ and $\gamma_{2}$ statistically significant, and $\gamma_{1}<0$, indicating that the conditional variance has a leverage effect. However, for the remainder, namely cattle (live cattle), cotton, soybeans and soy bean oil), the estimates of $\gamma_{1}$ and $\gamma_{2}$ are not statistically significant, meaning that an asymmetric effect of negative and positive shocks on conditional variance is not present. Therefore, the GARCH model is preferred to EGARCH for live cattle, soybeans, soybean oil and palm oil.

\section{[Insert Table 5 here]}

Table 5 presents the estimates of the $\operatorname{APARCH}(1,1)$ model from equation (7) for agricultural commodity futures returns. The power $(\delta)$ term estimated for APARCH is statistically significant for each of these commodity futures returns, ranging from 0.700 for Chicago wheat to 1.779 for soybean oil. The asymmetric $(\gamma)$ term in the $\operatorname{APARCH}(1,1)$ model is 
statistically significant in 7 of 16 cases, whereas only 5 commodities, namely coffee, soybeans, soybean meal, soybean oil, and Kansas City wheat, has $\gamma<0$, which means that these conditional volatilities have leverage effects. These results suggest that GARCH may not be appropriate for commodity futures returns.

\section{[Insert Table 6 here]}

The parameters estimated for the FIGARCH-BBM(1,1) and FIGARCH-Chung(1,1) models are summarized in Tables 6-7. Table 6 presents the estimated FIGARCH-BBM(1,1) from equation (9). The ARCH effects are statistically significant in 10 of 16 agricultural commodity futures returns, while the GARCH effects are statistically significant in 15 of 16 agricultural commodity futures returns. However, the sum of the ARCH(1) and GARCH(1) effects is greater than one in 6 commodities, namely live cattle, cattle feeder, cocoa, coffee, corn and cotton, which indicates nonstationarity. The estimated $d$ parameters in FIGARCH in all commodity futures returns lie between 0 and 1 , indicating the stability of the process, but for cotton the estimated $d$ parameter is not statically different from 0 , so it reduces to the GARCH model.

\section{[Insert Table 7 here]}

The results for the FIGARCH-Chung model from equation (13) are reported in Table 7, and mirror those in Table 6. The GARCH effects are statistically significant for 15 of 16 commodity futures returns, but the ARCH effects are statistically significant for 12 of 16 commodity futures returns. There are 6 commodities, namely live cattle, cattle feeder, cocoa, coffee, corn and cotton, for which the sum of the ARCH(1) and GARCH(1) effects is greater than 1 , indicating nonstationarity. However, the estimated $d$ parameters in the FIGARCHChung model in all agricultural commodity futures returns are statistically significant, and lie between 0 and 1 , thereby indicating the stability of the process. Therefore, the FIGARCHChung model is preferred to FIGARCH-BBM.

\section{[Insert Table 8 here]}

Table 8 presents the estimates of the FIEGARCH(1,1) model from equation (16). The 
estimated $\gamma_{2}$ parameters are statistically significant in 9 of 16 agricultural commodity futures returns, meaning these returns have asymmetric effects of negative and positive shocks on the conditional variance. However, only for cattle feeder are both the estimates of $\gamma_{1}$ and $\gamma_{2}$ statistically significant, and $\gamma_{1}<0$, indicating that the conditional variance has a leverage effect. For the remainder, namely live cattle, coffee, cotton, soybeans, soybean oil, palm oil and rubber, the estimates of $\gamma_{1}$ and $\gamma_{2}$ are not statistically significant, such that an asymmetric effect of negative and positive shocks of equal magnitude on the conditional variance is not observed. Thus, for these agricultural commodity futures return series, the FIGARCH model is preferred to FIEGARCH. The estimated $d$ parameters in FIEGARCH are statistically significant in 9 of 16 cases and lie between 0 and 1, thereby indicating the stability of the process.

\section{[Insert Tables 9 and 10 here]}

Tables 9 and 10 show the estimates of the FIAPARCH(1,1) model of Tse (1998) and FIAPARCH(1,1) model of Chung (1999), respectively. Table 9 presents the estimates of the FIAPARCH(1,1) model of Tse (1998) for agricultural commodity futures returns. The power parameter estimates $(\delta)$ of all agricultural commodity futures returns are statistically significant, and range from 0.570 for live cattle to 2.184 for orange juice. The asymmetric $(\gamma)$ term in the FIAPARCH(1,1) model is statistically significant in 9 of 16 cases, but only 6 commodities, namely coffee, soybeans, soybean meal, soybean oil, Chicago wheat and Kansas City wheat, have $\gamma<0$, so that these conditional volatilities have leverage effects. In addition, the estimated $d$ for all agricultural commodity futures returns is statistically significant. Therefore, the FIGARCH model is not appropriate for modelling agricultural commodity futures returns.

Table 10 presents the estimates of the FIAPARCH(1,1) model of Chung (1999) for agricultural commodity futures returns. The power parameter estimates $(\delta)$ of all agricultural commodity futures returns are statistically significant, and range from 0.570 for live cattle to 2.184 for orange juice. The asymmetric $(\gamma)$ term in the $\operatorname{FIAPARCH}(1,1)$ model is statistically significant in 7 of 16 cases, but only for 4 commodities, namely coffee, soybeans, 
soybean oil, and Kansas City wheat, is $\gamma<0$, so that these conditional volatilities have leverage effects. In addition, the estimated $d$ parameters for all agricultural commodity futures returns are statistically significant, which leads to the same conclusion as FIAPARCH(1,1)-Chung, namely that FIGARCH is not appropriate for modelling commodity futures returns.

\section{Concluding Remarks}

The paper estimated the long memory volatility model in 16 agricultural commodity futures returns from different futures markets, namely CBOT for corn, oats, soybeans, soybean meal, soybean oil and wheat; CME for live cattle, cattle feeder and pork; NBOT for cocoa, coffee, cotton, and orange juice; KCBT for wheat; TOCOM for rubber (RSS3); and MDEX for palm oil. The class of fractional GARCH models, namely FIGARCH of Baillie et al. (1996), FIEGACH of Bollerslev and Mikkelsen (1996), and FIAPARCH of Tse (1998), were estimated and compared with the GARCH model of Bollerslev (1986), EGARCH of Nelson (1991), and APARCH of Ding et al. (1993).

The empirical results showed that, following the outcomes of the unit root tests, all agricultural commodity futures returns series were found to be stationary. The EGARCH $(1,1)$ model out-performed GARCH(1,1), and the APARCH model was also preferred to GARCH(1,1). The robust $t$ statistics of the estimated $d$ parameters, indicating long term dependence, suggested evidence of fractional integration in most agricultural commodity futures markets. Consequently, the fractionally integrated models, namely $\operatorname{FIGARCH}(1, d, 1)$ and FIEGARCH(1,d,1), performed significantly better than traditional conditional volatility models, such as GARCH(1,1) and $\operatorname{EGARCH}(1,1)$, for modelling agricultural commodity futures returns. 


\section{References}

Baillie, R., T. Bollerslev and H. Mikkelsen (1996), Fractionally Integrated Generalized Autoregressive Conditional Heteroskedasticity, Journal of Econometrics, 73, 5-59.

Baillie, R., Y. Han, R. Myers, and J. Song (2007), Long Memory Models for Daily and High Frequency Commodity Futures Returns, Journal of Futures Markets, 27, 643-668.

Baillie, R., Y. Han and T. Kwon (2002), Further Long Memory Properties of Inflationary Shocks, Southern Economic Journal, 68, 496-510.

Barkoulas, J., W. Labys and J. Onochie (1997), Fractional Dynamics in International Commodity Prices, Journal of Futures Markets, 17, 161-189.

Bollerslev, T. (1986), Generalized Autoregressive Conditional Heteroscedasticity, Journal of Econometrices, 31, 307-327.

Bollerslev, T. and H. Mikkelsen (1996), Modeling and Pricing Long Memory in Stock Market Volatility, Journal of Econometrics, 73, 151-184.

Brunetti, C. and C. Gilbert (2000), Bivariate FIGARCH and Fractional Cointegration, Journal of Empirical Finance, 7, 509-530.

Chung, C. (1999), Estimating the Fractionally Integrated GARCH Model, unpublished paper, National Taiwan University.

Coakley, J., J. Dollery and N. Kellard (2008), The Role of Long Memory in Hedging Effectiveness, Computational Statistics and Data Analysis, 52, 3075-3082.

Conrad, C. and M. Lamla (2007), The High-Frequency Response of the EUR-US Dollar Exchange Rate to ECB Monetary Policy Announcements, KOF Working Papers, No 174.

Crato, N. and B. Ray (2000), Memory in Returns and Volatilities of Futures Contracts, Journal of Futures Markets, 20, 525-543.

Davidson, J. (2004), Moment and Memory Properties of Linear Conditional Heteroscedasticity Models, and A New Model, Journal of Business and Economic Statistics, 22, 16-29.

Degiannakis, S. (2004), Volatility Forecasting: Evidence from a Fractional Integrated Asymmetric Power ARCH Skewed-t Model, Applied Financial Economics, 14, 13331342.

Ding, Z., C. Granger and R. Engle (1993), A Long Memory Property of Stock Market Returns and a New Model, Journal of Empirical Finance 1, 83-106. 
Engle, R.F. (1982), Autoregressive Conditional Heteroscedasticity with Estimates of the Variance of United Kingdom Inflation, Econometrica, 55, 391-407.

Engle, R.F. and T. Bollerslev (1986), Modeling the persistence of conditional variances, Econometric Reviews, 5, 1-50.

Geweke, J. (1986), Modeling the Persistence of Conditional Variances: A Comment, Econometric Reviews, 5, 57-61.

Glosten, L., R. Jagannathan and D. Runkle (1992), On the Relation between the Expected Value and Volatiltiy and of the Nominal Excess Returns on Stocks, Journal of Finance, 46, 1779-1801.

Higgins, M. and A. Bera (1992), A Class of Nonlinear ARCH Models, International Economic Review, 33, 137-158.

Hyun-Joung, J. (2008), A Long Memory Conditional Variance Model for International Grain Markets, Journal of Rural Development, 31, 81-103.

Jefferis, K. and P. Thupayagale (2008), Long Memory in Southern Africa Stock Markets, South African Journal of Economics, 73, 384-398.

Jin, H. and D. Frechette (2004), Fractional Integration in Agricultural Futures Price Volatilities, American Journal of Agricultural Economics, 86, 432-443.

Kang, S. and S. Yoon (2007), Long Memory Properties in Return and Volatility: Evidence from the Korean Stock Market, Physica A, 385, 591-600.

Laurent S. and J. Peters (2006), G@RCH 4.2, Estimating and Forecasting ARCH Models, London, Timberlake Consultants.

Ling, S. and M. McAleer (2002), Necessary and Sufficient Moment Conditions for the GARCH(r,s) and Asymmetric Power GARCH(r,s) Models, Econometric Theory, 18, 722-729.

Lux, T. and T. Kaizoji (2007), Forecasting Volatility and Volume in the Tokyo Stock Market: Long Memory, Fractality and Regime Switching, Journal of Economic Dynamics and Control, 31, 1808-1843.

McAleer, M. (2005), Automated Inference and Learning in Modeling Financial Volatility, Econometric Theory, 21, 232-261.

McAleer, M., F. Chan, and D. Marinova (2007), An Econometric Analysis of Asymmetric Volatility: Theory and Application to Patents, Journal of Econometrics, 139, 259-284.

Nelson, D. (1991), Conditional Heteroskedasticity in Asset Returns: A New Approach, Econometrica, 59, 347-370. 
Ñiguez, T. (2007), Volatility and VaR Forecasting in the Madrid Stock Exchange, Spanish Economic Review, 10, 169-196

Pantula, S. (1986), Modeling the Persistence of Conditional Variances: A Comment, Econometric Reviews, 5, 71-74.

Poon, S. and C. Granger (2003), Forecasting Volatility in Financial Markets: A Review, Journal of Economic Literature, XLI, 478-539.

Ruiz, E. and H. Veiga (2008), Modelling Long-Memory Volatilities with Leverage Effect: ALMSV versus FIEGARCH, Computational Statistics and Data Analysis, 52, 28462862.

Schwert, W. (1990), Stock Volatility and the Crash of '87. Review of Financial Studies, 3, 77-102.

Sephton, P. (2009), Fractional integration in agricultural futures price volatilities revisited. Agricultural Economics, 40, 103-111.

Taylor, S. (1986), Modelling Financial Time Series. New York, Wiley.

Tse, Y. (1998), The Conditional Heteroscedasticity of the Yen-Dollar Exchange Rate, Journal of Applied Econometrics, 193, 49-55.

Zakoian, J. (1994), Threshold Heteroskedasticity Models, Journal of Economic Dynamics and Control, 15, 931-955. 
Table 1. Descriptive Statistics for Agricultural Commodity Futures Returns

\begin{tabular}{lccccccr}
\hline Commodity & Mean & Max & Min & S.D. & Skewness & Kurtosis & Jarque-Bera \\
\hline cattlef & 0.001 & 2.950 & -2.610 & 0.408 & -0.047 & 5.818 & 2613.18 \\
cattlel & 0.002 & 3.962 & -4.224 & 0.473 & -0.392 & 10.139 & 16955.27 \\
cocoany & -0.002 & 5.455 & -5.435 & 0.843 & 0.086 & 6.168 & 3307.76 \\
coffee & -0.0009 & 10.324 & -8.337 & 0.994 & 0.164 & 10.908 & 20589.09 \\
corn & 0.003 & 4.256 & -9.403 & 0.649 & -0.362 & 14.890 & 46640.28 \\
cotton & -0.002 & 7.257 & -32.538 & 0.785 & -9.469 & 388.23 & 48891741 \\
oats & 0.002 & 5.618 & -8.693 & 0.867 & 0.030 & 8.557 & 10152.27 \\
orange & -0.003 & 10.378 & -6.001 & 0.800 & 0.592 & 15.693 & 53412.20 \\
pork & 0.002 & 24.890 & -14.843 & 1.111 & 3.606 & 76.760 & 1805221 \\
soybean & 0.002 & 3.276 & -5.391 & 0.627 & -9.350 & 6.882 & 5114.587 \\
soymeal & 0.003 & 3.855 & -6.507 & 0.675 & -0.330 & 7.819 & 7776.195 \\
soyoil & 0.002 & 3.786 & -3.912 & 0.672 & 0.093 & 4.981 & 1301.018 \\
wheatc & 0.003 & 4.055 & -6.949 & 0.717 & -0.085 & 9.085 & 12179.78 \\
wheatk & 0.003 & 3.776 & -6.339 & 0.620 & -0.171 & 9.189 & 12627.68 \\
palm & 0.008 & 6.638 & -7.359 & 0.781 & 0.031 & 11.503 & 22369.98 \\
rubber & 0.005 & 8.580 & -9.684 & 0.998 & -0.547 & 11.176 & 14207.00 \\
\hline
\end{tabular}


Table 2. Unit Root Tests for Returns

\begin{tabular}{lcccccccc}
\hline \multirow{2}{*}{ Commodity } & \multicolumn{3}{c}{ Augmented Dicky-Fuller } & \multicolumn{3}{c}{ Phillip-Peron } & \multicolumn{2}{c}{ KPSS } \\
\cline { 2 - 9 } cattlef & $\mathbf{N}$ & $\mathbf{C}$ & $\mathbf{C \& T}$ & $\mathbf{N}$ & $\mathbf{C}$ & $\mathbf{C \& T}$ & $\mathbf{C}$ & $\mathbf{C \& T}$ \\
\cline { 2 - 9 } cattlel & -85.464 & -85.459 & -85.454 & -85.409 & -85.404 & -85.400 & 0.036 & 0.027 \\
cocoany & -85.863 & -85.858 & -85.853 & -85.820 & -85.815 & -85.810 & 0.011 & 0.012 \\
coffee & -88.423 & -88.418 & -88.435 & -88.423 & -88.418 & -88.438 & 0.206 & 0.019 \\
corn & -88.719 & -88.714 & -88.709 & -88.736 & -88.730 & -88.725 & 0.036 & 0.029 \\
cotton & -84.407 & -84.404 & -84.400 & -84.394 & -84.391 & -84.387 & 0.057 & 0.039 \\
oats & -87.648 & -87.643 & -87.638 & -87.640 & -87.635 & -87.630 & 0.020 & 0.015 \\
orange & -84.353 & -84.348 & -84.343 & -84.355 & -84.351 & -84.345 & 0.025 & 0.025 \\
pork & -64.808 & -64.805 & -64.802 & -87.357 & -87.33 & -87.348 & 0.035 & 0.028 \\
soybean & -84.964 & -84.959 & -84.954 & -85.010 & -85.005 & -85.000 & 0.014 & 0.011 \\
soymeal & -88.635 & -88.630 & -88.629 & -88.682 & -88.677 & -88.675 & 0.063 & 0.026 \\
soyoil & -86.635 & -86.631 & -86.629 & -86.637 & -86.629 & -86.626 & 0.049 & 0.024 \\
wheatc & -87.113 & -87.108 & -87.106 & -87.139 & -87.134 & -87.131 & 0.058 & 0.028 \\
wheatk & -87.264 & -87.259 & -87.255 & -87.353 & -87.348 & -87.345 & 0.051 & 0.032 \\
palm & -84.906 & -84.903 & -84.899 & -84.909 & -84.906 & -84.902 & 0.055 & 0.038 \\
rubber & -35.215 & -35.221 & -35.219 & -84.210 & -84.195 & -84.191 & 0.023 & 0.022 \\
\hline
\end{tabular}

Note: All entries are significant at the $1 \%$ level. 
Table 3. Estimated GARCH(1,1) Models

\begin{tabular}{|c|c|c|c|c|c|}
\hline Commodity & $\omega$ & $\alpha$ & $\beta$ & AIC & SIC \\
\hline \multirow[t]{2}{*}{ cattlef } & 0.001 & 0.029 & 0.967 & 0.919 & 0.917 \\
\hline & 2.503 & 5.082 & 135.1 & & \\
\hline \multirow[t]{2}{*}{ cattlel } & 0.001 & 0.009 & 0.988 & 1.287 & 1.285 \\
\hline & 2.334 & 4.411 & 334.6 & & \\
\hline \multirow[t]{2}{*}{ cocoa } & 0.004 & 0.027 & 0.969 & 2.427 & 2.425 \\
\hline & 2.382 & 5.368 & 155.9 & & \\
\hline \multirow[t]{2}{*}{ coffee } & 0.008 & 0.060 & 0.936 & 2.620 & 2.619 \\
\hline & 2.566 & 6.275 & 91.10 & & \\
\hline \multirow[t]{2}{*}{ corn } & 0.016 & 0.090 & 0.874 & 1.806 & 1.805 \\
\hline & 1.029 & 1.263 & 8.702 & & \\
\hline \multirow[t]{2}{*}{ cotton } & 0.112 & 0.022 & 0.801 & 2.351 & 2.350 \\
\hline & 0.996 & 0.617 & 6.106 & & \\
\hline \multirow[t]{2}{*}{ oats } & 0.052 & 0.124 & 0.815 & 2.451 & 2.450 \\
\hline & 2.972 & 4.170 & 18.12 & & \\
\hline \multirow[t]{2}{*}{ orange } & 0.004 & 0.044 & 0.953 & 2.280 & 2.278 \\
\hline & 1.380 & 2.075 & 43.40 & & \\
\hline \multirow[t]{2}{*}{ pork } & 0.016 & 0.136 & 0.877 & 2.875 & 2.874 \\
\hline & 1.739 & 5.628 & 51.05 & & \\
\hline \multirow[t]{2}{*}{ soybean } & 0.004 & 0.062 & 0.929 & 1.707 & 1.706 \\
\hline & 4.085 & 10.95 & 146.9 & & \\
\hline \multirow[t]{2}{*}{ soymeal } & 0.006 & 0.053 & 0.936 & 1.897 & 1.896 \\
\hline & 2.985 & 7.478 & 101.3 & & \\
\hline \multirow[t]{2}{*}{ soyoil } & 0.008 & 0.048 & 0.935 & 1.935 & 1.934 \\
\hline & 3.736 & 6.625 & 85.83 & & \\
\hline \multirow[t]{2}{*}{ wheatc } & 0.009 & 0.036 & 0.947 & 2.072 & 2.070 \\
\hline & 1.805 & 3.281 & 48.51 & & \\
\hline \multirow[t]{2}{*}{ wheatk } & 0.011 & 0.085 & 0.891 & 1.703 & 1.702 \\
\hline & 0.664 & 0.960 & 7.306 & & \\
\hline \multirow[t]{2}{*}{ palm } & 0.009 & 0.102 & 0.886 & 1.839 & 1.837 \\
\hline & 3.626 & 8.824 & 66.72 & & \\
\hline \multirow[t]{2}{*}{ rubber } & 0.035 & 0.110 & 0.861 & 1.686 & 1.685 \\
\hline & 2.633 & 3.960 & 24.53 & & \\
\hline
\end{tabular}

Notes: (1) The two entries for each parameter are their respective parameter estimates and robust $t$ - ratios. (2) Entries in bold are significant at the $5 \%$ level. 


\section{Table 4. Estimated EGARCH(1,1) Models}

\begin{tabular}{|c|c|c|c|c|c|c|c|}
\hline Commodity & $\omega$ & $\alpha$ & $\beta$ & $\gamma_{1}$ & $\gamma_{2}$ & AIC & SIC \\
\hline \multirow[t]{2}{*}{ cattlef } & -1.503 & 0.028 & 0.993 & $\begin{array}{c}-0.037 \\
\end{array}$ & 0.051 & 0.903 & 0.901 \\
\hline & -12.25 & 0.063 & 501.5 & -2.371 & 2.312 & & \\
\hline \multirow[t]{2}{*}{ cattlel } & -1.117 & 3.372 & 0.994 & -0.002 & 0.007 & 1.061 & 1.059 \\
\hline & -4.969 & 0.678 & 296.4 & -0.564 & 0.852 & & \\
\hline \multirow[t]{2}{*}{ cocoany } & 0.147 & -0.078 & 0.991 & 0.015 & 0.082 & 2.424 & 2.422 \\
\hline & 0.753 & -0.204 & 339.8 & 1.404 & 2.394 & & \\
\hline \multirow[t]{2}{*}{ coffee } & 0.909 & -0.244 & 0.989 & 0.042 & 0.188 & 2.290 & 2.288 \\
\hline & 2.612 & -1.661 & 302.4 & 3.215 & 5.804 & & \\
\hline \multirow[t]{2}{*}{ corn } & -0.542 & -0.616 & 0.981 & -0.029 & 0.286 & 1.790 & 1.788 \\
\hline & -3.806 & -5.060 & 165.5 & -0.880 & 3.192 & & \\
\hline \multirow[t]{2}{*}{ cotton } & -0.432 & 0.206 & 0.839 & 0.045 & 0.043 & 2.349 & 2.347 \\
\hline & -3.004 & 0.156 & 4.973 & 0.561 & 1.141 & & \\
\hline \multirow[t]{2}{*}{ oats } & -0.001 & -0.428 & 0.965 & -0.009 & 0.257 & 2.440 & 2.439 \\
\hline & -0.008 & -2.290 & 61.82 & -0.429 & 5.713 & & \\
\hline \multirow[t]{2}{*}{ orange } & 0.415 & -0.329 & 0.986 & -0.011 & 0.163 & 2.272 & 2.270 \\
\hline & 1.337 & -1.028 & 112.2 & -0.625 & 4.624 & & \\
\hline \multirow[t]{2}{*}{ pork } & 0.519 & 0.240 & 0.992 & -0.027 & 0.086 & 2.735 & 2.734 \\
\hline & 1.040 & 0.468 & 236.5 & -2.088 & 2.064 & & \\
\hline \multirow[t]{2}{*}{ soybean } & -0.540 & 1.435 & 0.987 & 0.011 & 0.059 & 1.701 & 1.699 \\
\hline & -3.060 & 1.090 & 336.3 & 1.716 & 1.832 & & \\
\hline \multirow[t]{2}{*}{ soymeal } & -0.417 & -0.027 & 0.984 & 0.024 & 0.120 & 1.892 & 1.890 \\
\hline & -2.781 & -0.092 & 230.9 & 2.586 & 3.336 & & \\
\hline \multirow[t]{2}{*}{ soyoil } & -0.582 & 1.184 & 0.982 & 0.007 & 0.050 & 1.939 & 1.937 \\
\hline & -6.521 & 0.780 & 185.8 & 0.991 & 1.466 & & \\
\hline \multirow[t]{2}{*}{ wheatc } & -0.421 & -0.410 & 0.983 & 0.028 & 0.159 & 2.058 & 2.056 \\
\hline & -3.221 & -1.907 & 128.7 & 0.988 & 3.302 & & \\
\hline \multirow[t]{2}{*}{ wheatk } & -0.657 & -0.457 & 0.979 & 0.057 & 0.238 & 1.687 & 1.685 \\
\hline & -5.355 & -3.794 & 126.2 & 2.655 & 5.799 & & \\
\hline \multirow[t]{2}{*}{ palm } & -0.054 & 0.248 & 0.974 & 0.010 & 0.169 & 1.847 & 1.845 \\
\hline & -0.324 & 0.903 & 169.2 & 1.403 & 4.833 & & \\
\hline \multirow[t]{2}{*}{ rubber } & 0.343 & -0.583 & 0.971 & 0.001 & 0.387 & 1.680 & 1.678 \\
\hline & 1.938 & -6.038 & 85.46 & 0.018 & 6.549 & & \\
\hline
\end{tabular}

Notes: (1) The two entries for each parameter are their respective parameter estimates and robust $t$ - ratios. (2) Entries in bold are significant at the 5\% level. 
Table 5. Estimated APARCH(1,1) Models

\begin{tabular}{|c|c|c|c|c|c|c|c|}
\hline Commodity & $\omega$ & $\alpha$ & $\beta$ & $\gamma$ & $\delta$ & AIC & SIC \\
\hline \multirow[t]{2}{*}{ cattlef } & 0.002 & 0.027 & 0.972 & 0.624 & 1.176 & 0.903 & 0.901 \\
\hline & 2.362 & 4.276 & 160.6 & 4.953 & 8.747 & & \\
\hline \multirow[t]{2}{*}{ cattlel } & 0.003 & 0.016 & 0.983 & 0.337 & 0.936 & 1.063 & 1.062 \\
\hline & 1.563 & 3.605 & 161.3 & 1.544 & 6.264 & & \\
\hline \multirow[t]{2}{*}{ cocoany } & 0.005 & 0.037 & 0.965 & -0.090 & 1.245 & 2.423 & 2.421 \\
\hline & 2.442 & 6.695 & 163.0 & -1.028 & 7.124 & & \\
\hline \multirow[t]{2}{*}{ coffee } & 0.010 & 0.071 & 0.935 & -0.159 & 1.427 & 2.615 & 2.613 \\
\hline & 2.806 & 6.776 & 94.03 & -2.627 & 10.10 & & \\
\hline \multirow[t]{2}{*}{ corn } & 0.017 & 0.080 & 0.914 & 0.158 & 1.095 & 1.794 & 1.792 \\
\hline & 1.852 & 2.176 & 20.99 & 1.514 & 4.737 & & \\
\hline \multirow[t]{2}{*}{ cotton } & 0.002 & 0.033 & 0.974 & -0.130 & 1.021 & 1.967 & 1.965 \\
\hline & 1.133 & 4.773 & 122.5 & -0.633 & 4.221 & & \\
\hline \multirow[t]{2}{*}{ oats } & 0.045 & 0.108 & 0.869 & 0.049 & 1.032 & 2.440 & 2.439 \\
\hline & 2.899 & 4.560 & 25.43 & 0.748 & 9.013 & & \\
\hline \multirow[t]{2}{*}{ orange } & 0.008 & 0.058 & 0.950 & 0.068 & 1.202 & 2.272 & 2.2707 \\
\hline & 1.425 & 2.466 & 44.09 & 0.641 & 6.630 & & \\
\hline \multirow[t]{2}{*}{ pork } & 0.006 & 0.070 & 0.945 & 0.444 & 0.858 & 2.825 & 2.824 \\
\hline & 1.636 & 5.849 & 113.4 & 3.518 & 12.04 & & \\
\hline \multirow[t]{2}{*}{ soybean } & 0.006 & 0.071 & 0.935 & -0.186 & 1.240 & 1.701 & 1.699 \\
\hline & 3.700 & 10.75 & 162.6 & -3.487 & 7.972 & & \\
\hline \multirow[t]{2}{*}{ soymeal } & 0.010 & 0.061 & 0.941 & -0.226 & 1.039 & 1.889 & 1.888 \\
\hline & 3.479 & 7.960 & 112.4 & -2.758 & 6.768 & & \\
\hline \multirow[t]{2}{*}{ soyoil } & 0.008 & 0.049 & 0.939 & -0.127 & 1.779 & 1.935 & 1.933 \\
\hline & 3.543 & 6.549 & 81.92 & -2.814 & 10.34 & & \\
\hline \multirow[t]{2}{*}{ wheatc } & 0.014 & 0.051 & 0.945 & -0.200 & 0.700 & 2.055 & 2.053 \\
\hline & 2.869 & 5.665 & 82.52 & -1.779 & 5.667 & & \\
\hline \multirow[t]{2}{*}{ wheatk } & 0.012 & 0.073 & 0.925 & -0.223 & 1.074 & 1.687 & 1.685 \\
\hline & 2.814 & 5.053 & 52.11 & -2.621 & 7.527 & & \\
\hline \multirow[t]{2}{*}{ palm } & 0.010 & 0.106 & 0.890 & -0.057 & 1.780 & 1.838 & 1.836 \\
\hline & 3.720 & 8.975 & 69.52 & -1.574 & 11.09 & & \\
\hline \multirow[t]{2}{*}{ rubber } & 0.037 & 0.117 & 0.870 & -0.015 & 1.507 & 1.685 & 1.684 \\
\hline & 2.941 & 4.777 & 28.75 & -0.220 & 7.973 & & \\
\hline
\end{tabular}

Notes: (1) The two entries for each parameter are their respective parameter estimates and robust $t$ - ratios. (2) Entries in bold are significant at the $5 \%$ level 
Table 6. Estimated FIGARCH(1,1)-BBM Models

\begin{tabular}{|c|c|c|c|c|c|c|}
\hline Commodity & $\omega$ & $d$ & $\alpha$ & $\beta$ & AIC & SIC \\
\hline \multirow[t]{2}{*}{ cattlef } & 0.008 & 0.317 & 0.383 & 0.648 & 0.9172 & 0.916 \\
\hline & 2.866 & 8.382 & 7.048 & 10.16 & & \\
\hline \multirow[t]{2}{*}{ cattlel } & 0.025 & 0.186 & 0.526 & 0.681 & 1.293 & 1.291 \\
\hline & 2.771 & 5.887 & 5.062 & 7.428 & & \\
\hline \multirow[t]{2}{*}{ cocoany } & 0.008 & 0.317 & 0.383 & 0.648 & 0.917 & 0.916 \\
\hline & 2.866 & 8.382 & 7.048 & 10.16 & & \\
\hline \multirow[t]{2}{*}{ coffee } & 0.019 & 0.431 & 0.404 & 0.716 & 2.611 & 2.609 \\
\hline & 3.204 & 7.607 & 7.822 & 16.40 & & \\
\hline \multirow[t]{2}{*}{ corn } & 0.031 & 0.278 & 0.452 & 0.555 & 1.791 & 1.789 \\
\hline & 1.916 & 5.865 & 2.310 & 2.892 & & \\
\hline \multirow[t]{2}{*}{ cotton } & 0.085 & -0.009 & 0.874 & 0.849 & 2.351 & 2.350 \\
\hline & 1.489 & -0.723 & 9.280 & 7.167 & & \\
\hline \multirow[t]{2}{*}{ oats } & 0.085 & 0.283 & 0.191 & 0.321 & 2.440 & 2.439 \\
\hline & 1.798 & 6.228 & 0.686 & 1.108 & & \\
\hline \multirow[t]{2}{*}{ orange } & 0.057 & 0.295 & 0.226 & 0.439 & 2.269 & 2.267 \\
\hline & 2.300 & 8.201 & 1.259 & 2.450 & & \\
\hline \multirow[t]{2}{*}{ pork } & 0.035 & 0.935 & -0.119 & 0.817 & 2.867 & 2.866 \\
\hline & 3.229 & 12.99 & -1.981 & 21.66 & & \\
\hline \multirow[t]{2}{*}{ soybean } & 0.003 & 0.982 & -0.014 & 0.924 & 1.709 & 1.708 \\
\hline & 2.683 & 11.36 & -0.222 & 34.93 & & \\
\hline \multirow[t]{2}{*}{ soymeal } & 0.019 & 0.375 & 0.338 & 0.631 & 1.898 & 1.897 \\
\hline & 2.031 & 4.903 & 4.841 & 5.719 & & \\
\hline \multirow[t]{2}{*}{ soyoil } & 0.023 & 0.344 & 0.276 & 0.592 & 1.932 & 1.931 \\
\hline & 3.958 & 9.458 & 7.788 & 12.93 & & \\
\hline \multirow[t]{2}{*}{ wheatc } & 0.060 & 0.216 & 0.402 & 0.533 & 2.068 & 2.066 \\
\hline & 2.054 & 5.171 & 2.630 & 3.347 & & \\
\hline \multirow[t]{2}{*}{ wheatk } & 0.038 & 0.309 & 0.153 & 0.342 & 1.693 & 1.691 \\
\hline & 2.639 & 5.378 & 1.006 & 2.634 & & \\
\hline \multirow[t]{2}{*}{ palm } & 0.025 & 0.451 & 0.074 & 0.419 & 1.835 & 1.834 \\
\hline & 2.961 & 7.399 & 0.860 & 3.411 & & \\
\hline \multirow[t]{2}{*}{ rubber } & 0.052 & 0.335 & 0.471 & 0.600 & 1.677 & 1.676 \\
\hline & 1.666 & 4.345 & 2.463 & 3.063 & & \\
\hline
\end{tabular}

Notes: (1) The two entries for each parameter are their respective parameter estimates and robust $t$ - ratios. (2) Entries in bold are significant at the 5\% level. 
Table 7. Estimated FIGARCH(1,1)-Chung Models

\begin{tabular}{|c|c|c|c|c|c|c|}
\hline Commodity & $\omega$ & $d$ & $\alpha$ & $\beta$ & AIC & SIC \\
\hline \multirow[t]{2}{*}{ cattlef } & 0.177 & 0.341 & 0.373 & 0.661 & 0.918 & 0.917 \\
\hline & 4.886 & 7.784 & 7.009 & 10.09 & & \\
\hline \multirow[t]{2}{*}{ cattlel } & 0.229 & 0.194 & 0.521 & 0.683 & 1.294 & 1.293 \\
\hline & 8.738 & 5.603 & 4.965 & 7.369 & & \\
\hline \multirow[t]{2}{*}{ cocoany } & 0.713 & 0.340 & 0.405 & 0.696 & 2.429 & 2.427 \\
\hline & 5.801 & 8.789 & 9.284 & 15.63 & & \\
\hline \multirow[t]{2}{*}{ coffee } & 0.753 & 0.402 & 0.417 & 0.701 & 2.611 & 2.609 \\
\hline & 2.374 & 8.556 & 8.338 & 15.80 & & \\
\hline \multirow[t]{2}{*}{ corn } & 0.423 & 0.251 & 0.465 & 0.554 & 1.792 & 1.790 \\
\hline & 4.566 & 6.872 & 2.300 & 2.845 & & \\
\hline \multirow[t]{2}{*}{ cotton } & 0.452 & 0.387 & 0.359 & 0.714 & 1.985 & 1.984 \\
\hline & 3.680 & 12.73 & 10.10 & 21.33 & & \\
\hline \multirow[t]{2}{*}{ oats } & 0.815 & 0.259 & 0.189 & 0.304 & 2.441 & 2.440 \\
\hline & 5.644 & 6.752 & 0.612 & 0.953 & & \\
\hline \multirow[t]{2}{*}{ orange } & 0.579 & 0.271 & 0.232 & 0.427 & 2.270 & 2.270 \\
\hline & 4.572 & 9.713 & 1.246 & 2.265 & & \\
\hline \multirow[t]{2}{*}{ pork } & 1.949 & 0.483 & 0.245 & 0.673 & 2.717 & 2.716 \\
\hline & 2.290 & 9.418 & 4.970 & 14.34 & & \\
\hline \multirow[t]{2}{*}{ soybean } & 0.490 & 0.472 & 0.233 & 0.665 & 1.711 & 1.710 \\
\hline & 2.875 & 7.383 & 5.852 & 8.618 & & \\
\hline \multirow[t]{2}{*}{ soymeal } & 0.426 & 0.341 & 0.343 & 0.607 & 1.899 & 1.898 \\
\hline & 4.573 & 6.086 & 4.663 & 6.094 & & \\
\hline \multirow[t]{2}{*}{ soyoil } & 0.466 & 0.344 & 0.277 & 0.593 & 1.932 & 1.931 \\
\hline & 5.327 & 10.11 & 8.007 & 13.16 & & \\
\hline \multirow[t]{2}{*}{ wheatc } & 0.517 & 0.207 & 0.401 & 0.526 & 2.068 & 2.067 \\
\hline & 7.706 & 5.272 & 2.545 & 3.194 & & \\
\hline \multirow[t]{2}{*}{ wheatk } & 0.354 & 0.259 & 0.167 & 0.318 & 1.694 & 1.693 \\
\hline & 3.743 & 8.001 & 1.090 & 2.165 & & \\
\hline \multirow[t]{2}{*}{ palm } & 1.024 & 0.449 & 0.083 & 0.425 & 1.836 & 1.834 \\
\hline & 1.972 & 9.195 & 1.020 & 3.928 & & \\
\hline \multirow[t]{2}{*}{ rubber } & 1.112 & 0.310 & 0.486 & 0.599 & 1.678 & 1.677 \\
\hline & 3.082 & 5.927 & 2.390 & 2.995 & & \\
\hline
\end{tabular}

Notes: (1) The two entries for each parameter are their respective parameter estimates and robust $t$ - ratios. (2) Entries in bold are significant at the 5\% level. 
Table 8. Estimated FIEGARCH(1,1) Models

\begin{tabular}{|c|c|c|c|c|c|c|c|c|}
\hline Commodity & $\omega$ & $d$ & $\alpha$ & $\beta$ & $\gamma_{1}$ & $\gamma_{2}$ & AIC & SIC \\
\hline \multirow[t]{2}{*}{ cattlef } & -1.115 & 0.671 & 0.199 & 0.594 & -0.036 & 0.041 & 0.897 & 0.896 \\
\hline & -6.773 & 12.08 & 0.273 & 3.440 & -2.179 & 2.054 & & \\
\hline \multirow[t]{2}{*}{ cattlel } & -0.749 & 0.712 & 2.348 & -0.871 & -0.019 & 0.033 & 1.268 & 1.266 \\
\hline & -3.099 & 7.814 & 1.252 & -8.347 & -1.044 & 1.361 & & \\
\hline \multirow[t]{2}{*}{ cocoany } & 0.157 & 0.102 & -0.264 & 0.986 & 0.015 & 0.082 & 2.425 & 2.422 \\
\hline & 0.904 & 0.305 & -0.428 & 44.32 & 1.386 & 2.412 & & \\
\hline \multirow[t]{2}{*}{ coffee } & 0.967 & 0.329 & -0.641 & 0.946 & 0.041 & 0.200 & 2.613 & 2.612 \\
\hline & 3.828 & 3.622 & -5.960 & 28.95 & 2.953 & 6.074 & & \\
\hline \multirow[t]{2}{*}{ corn } & -0.302 & 0.236 & -0.794 & 0.958 & -0.031 & 0.306 & 1.791 & 1.790 \\
\hline & -1.373 & 2.238 & -8.174 & 40.68 & -0.902 & 3.438 & & \\
\hline \multirow[t]{2}{*}{ cotton } & -0.439 & 0.086 & 2.979 & -0.261 & 0.057 & 0.063 & 2.343 & 2.341 \\
\hline & -3.396 & 0.259 & 1.558 & -0.798 & 1.438 & 1.347 & & \\
\hline \multirow[t]{2}{*}{ oats } & 0.372 & 0.361 & -0.348 & 0.749 & -0.010 & 0.262 & 2.435 & 2.433 \\
\hline & 1.821 & 3.877 & -0.600 & 2.501 & -0.456 & 5.408 & & \\
\hline \multirow[t]{2}{*}{ orange } & 0.719 & 0.473 & 0.202 & 0.532 & -0.0001 & 0.150 & 2.263 & 2.262 \\
\hline & 3.034 & 10.82 & 0.336 & 4.882 & -0.014 & 3.784 & & \\
\hline \multirow[t]{2}{*}{ pork } & 0.590 & 0.301 & -0.326 & 0.967 & -0.027 & 0.088 & 2.734 & 2.733 \\
\hline & 1.325 & 2.052 & -0.999 & 52.04 & 1.904 & 2.026 & & \\
\hline \multirow[t]{2}{*}{ soybean } & -0.409 & 0.195 & 0.785 & 0.969 & 0.011 & 0.056 & 1.701 & 1.699 \\
\hline & -2.024 & 1.836 & 0.721 & 66.44 & 1.701 & 1.781 & & \\
\hline \multirow[t]{2}{*}{ soymeal } & -0.179 & 0.300 & -0.363 & 0.937 & 0.028 & 0.119 & 1.893 & 1.891 \\
\hline & -0.586 & 1.387 & -1.376 & 15.18 & 2.552 & 3.078 & & \\
\hline \multirow[t]{2}{*}{ soyoil } & -0.283 & 0.454 & 0.859 & 0.827 & 0.007 & 0.045 & 1.936 & 1.934 \\
\hline & -1.863 & 7.069 & 0.624 & 15.01 & 1.085 & 1.449 & & \\
\hline \multirow[t]{2}{*}{ wheatc } & -0.298 & 0.254 & -0.666 & 0.949 & 0.037 & 0.166 & 2.057 & 2.055 \\
\hline & -2.103 & 1.967 & -4.007 & 26.73 & 1.513 & 3.562 & & \\
\hline \multirow[t]{2}{*}{ wheatk } & -0.420 & 0.398 & -0.295 & 0.685 & 0.060 & 0.242 & 1.683 & 1.681 \\
\hline & -2.394 & 5.843 & -0.619 & 3.003 & 2.835 & 5.762 & & \\
\hline \multirow[t]{2}{*}{ palm } & -0.207 & -0.226 & 0.966 & 0.992 & 0.008 & 0.160 & 1.845 & 1.844 \\
\hline & -1.050 & -2.284 & 1.905 & 181.0 & 1.153 & 4.323 & & \\
\hline \multirow[t]{2}{*}{ rubber } & 0.873 & 0.321 & -0.771 & 0.921 & 0.0001 & 0.386 & 1.678 & 1.676 \\
\hline & 2.368 & 2.737 & -9.088 & 23.89 & 0.005 & 6.538 & & \\
\hline
\end{tabular}

Notes: (1) The two entries for each parameter are their respective parameter estimates and robust $t$ - ratios. (2) Entries in bold are significant at the 5\% level. 
Table 9. Estimated FIAPARCH(1,1)-BBM Models

\begin{tabular}{|c|c|c|c|c|c|c|c|c|}
\hline Commodity & $\omega$ & $d$ & $\alpha$ & $\beta$ & $\gamma$ & $\delta$ & AIC & SIC \\
\hline \multirow[t]{2}{*}{ cattlef } & 0.023 & 0.302 & 0.367 & 0.632 & 0.605 & 1.438 & 0.904 & 0.902 \\
\hline & 2.163 & 3.141 & 6.439 & 9.932 & 3.202 & 5.574 & & \\
\hline \multirow[t]{2}{*}{ cattlel } & 0.105 & 0.282 & 0.343 & 0.633 & 0.532 & 0.570 & 1.269 & 1.268 \\
\hline & 3.575 & 5.968 & 6.794 & 9.319 & 3.236 & 2.666 & & \\
\hline \multirow[t]{2}{*}{ cocoany } & 0.044 & 0.487 & 0.329 & 0.764 & -0.139 & 1.441 & 2.427 & 2.425 \\
\hline & 3.433 & 2.317 & 3.226 & 6.631 & -1.621 & 2.427 & & \\
\hline \multirow[t]{2}{*}{ coffee } & 0.016 & 0.405 & 0.405 & 0.696 & -0.132 & 2.042 & 2.609 & 2.607 \\
\hline & 1.431 & 5.897 & 6.663 & 14.78 & -2.385 & 14.31 & & \\
\hline \multirow[t]{2}{*}{ corn } & 0.051 & 0.414 & 0.378 & 0.626 & 0.079 & 1.422 & 1.787 & 1.785 \\
\hline & 1.957 & 5.685 & 2.756 & 4.862 & 0.795 & 4.603 & & \\
\hline \multirow[t]{2}{*}{ cotton } & 0.288 & 0.342 & 0.333 & 0.625 & 0.049 & 2.092 & 1.920 & 1.918 \\
\hline & 2.849 & 9.604 & 8.016 & 16.41 & 0.774 & 24.29 & & \\
\hline \multirow[t]{2}{*}{ oats } & 0.129 & 0.406 & 0.246 & 0.510 & 0.030 & 1.105 & 2.432 & 2.430 \\
\hline & 3.155 & 6.810 & 2.168 & 3.831 & 0.366 & 8.080 & & \\
\hline \multirow[t]{2}{*}{ orange } & 0.041 & 0.260 & 0.206 & 0.387 & 0.034 & 2.184 & 2.269 & 2.267 \\
\hline & 1.415 & 5.016 & 0.9544 & 1.681 & 0.413 & 8.244 & & \\
\hline \multirow[t]{2}{*}{ pork } & 1.197 & 0.385 & 0.225 & 0.605 & 0.771 & 1.605 & 2.846 & 2.844 \\
\hline & 1.398 & 5.705 & 2.548 & 4.757 & 3.255 & 17.34 & & \\
\hline \multirow[t]{2}{*}{ soybean } & 0.009 & 0.943 & -0.002 & 0.910 & -0.189 & 1.326 & 1.700 & 1.698 \\
\hline & 2.355 & 16.78 & -0.059 & 45.53 & -3.487 & 5.955 & & \\
\hline \multirow[t]{2}{*}{ soymeal } & 0.007 & 1.062 & -0.039 & 0.957 & -0.221 & 1.088 & 1.889 & 1.888 \\
\hline & 1.760 & 15.55 & -0.772 & 47.86 & -2.476 & 5.124 & & \\
\hline \multirow[t]{2}{*}{ soyoil } & 0.483 & 0.339 & 0.295 & 0.601 & -0.134 & 1.940 & 1.930 & 1.928 \\
\hline & 3.151 & 10.19 & 8.113 & 13.91 & -2.752 & 22.75 & & \\
\hline \multirow[t]{2}{*}{ wheatc } & 0.071 & 0.417 & 0.379 & 0.707 & -0.281 & 0.866 & 2.056 & 2.054 \\
\hline & 3.354 & 5.543 & 5.924 & 9.658 & -2.305 & 4.950 & & \\
\hline \multirow[t]{2}{*}{ wheatk } & 0.059 & 0.380 & 0.275 & 0.535 & -0.252 & 1.397 & 1.682 & 1.680 \\
\hline & 2.529 & 6.148 & 1.818 & 3.019 & -3.300 & 7.279 & & \\
\hline \multirow[t]{2}{*}{ palm } & 0.029 & 0.463 & 0.087 & 0.448 & -0.055 & 1.917 & 1.835 & 1.833 \\
\hline & 2.611 & 7.587 & 1.098 & 3.803 & -1.504 & 17.45 & & \\
\hline \multirow[t]{2}{*}{ rubber } & 0.063 & 0.430 & 0.445 & 0.667 & -0.021 & 1.707 & 1.677 & 1.675 \\
\hline & 2.309 & 2.914 & 3.865 & 4.619 & -0.282 & 5.942 & & \\
\hline
\end{tabular}

Notes: (1) The two entries for each parameter are their respective parameter estimates and robust $t$ - ratios. (2) Entries in bold are significant at the $5 \%$ level 
Table 10. Estimated FIAPARCH(1,1)-Chung Models

\begin{tabular}{|c|c|c|c|c|c|c|c|c|}
\hline Commodity & $\omega$ & $d$ & $\alpha$ & $\beta$ & $\gamma$ & $\delta$ & AIC & SIC \\
\hline \multirow[t]{2}{*}{ cattlef } & 0.428 & 0.297 & 0.369 & 0.629 & 0.604 & 1.434 & 0.903 & 0.901 \\
\hline & 4.844 & 9.006 & 9.125 & 13.61 & 4.719 & 15.14 & & \\
\hline \multirow[t]{2}{*}{ cattlel } & 0.738 & 0.187 & 0.361 & 0.540 & 0.867 & 1.071 & 1.272 & 1.271 \\
\hline & 5.080 & 6.670 & 5.371 & 7.315 & 2.727 & 11.21 & & \\
\hline \multirow[t]{2}{*}{ cocoany } & 0.735 & 0.342 & 0.399 & 0.696 & -0.100 & 1.977 & 2.428 & 2.426 \\
\hline & 3.984 & 8.679 & 9.713 & 16.40 & -1.475 & 22.29 & & \\
\hline \multirow[t]{2}{*}{ coffee } & 0.612 & 0.394 & 0.415 & 0.693 & -0.129 & 2.036 & 2.608 & 2.606 \\
\hline & 1.796 & 7.953 & 7.770 & 14.62 & -2.334 & 26.45 & & \\
\hline \multirow[t]{2}{*}{ corn } & 0.416 & 0.254 & 0.410 & 0.506 & 0.080 & 2.004 & 1.791 & 1.789 \\
\hline & 2.646 & 6.456 & 2.122 & 2.770 & 0.947 & 14.38 & & \\
\hline \multirow[t]{2}{*}{ cotton } & 0.289 & 0.341 & 0.333 & 0.625 & 0.049 & 2.092 & 1.920 & 1.918 \\
\hline & 2.849 & 9.604 & 8.016 & 16.41 & 0.774 & 24.29 & & \\
\hline \multirow[t]{2}{*}{ oats } & 0.850 & 0.264 & 0.133 & 0.271 & 0.118 & 1.961 & 2.440 & 2.438 \\
\hline & 2.722 & 7.394 & 0.520 & 1.032 & 1.595 & 14.71 & & \\
\hline \multirow[t]{2}{*}{ orange } & 0.247 & 0.237 & 0.189 & 0.350 & 0.052 & 2.239 & 2.267 & 2.265 \\
\hline & 2.232 & 7.340 & 0.798 & 1.444 & 0.670 & 20.58 & & \\
\hline \multirow[t]{2}{*}{ pork } & 1.197 & 0.385 & 0.225 & 0.605 & 0.771 & 1.605 & 2.846 & 2.844 \\
\hline & 1.398 & 5.705 & 2.548 & 4.757 & 3.255 & 17.34 & & \\
\hline \multirow[t]{2}{*}{ soybean } & 0.495 & 0.487 & 0.242 & 0.699 & -0.196 & 1.943 & 1.707 & 1.705 \\
\hline & 2.478 & 8.227 & 7.835 & 12.23 & -3.672 & 26.02 & & \\
\hline \multirow[t]{2}{*}{ soymeal } & 0.422 & 0.354 & 0.348 & 0.631 & -0.147 & 1.964 & 1.897 & 1.895 \\
\hline & 2.821 & 6.844 & 5.817 & 7.847 & -1.906 & 19.05 & & \\
\hline \multirow[t]{2}{*}{ soyoil } & 0.483 & 0.339 & 0.295 & 0.601 & -0.134 & 1.940 & 1.931 & 1.929 \\
\hline & 3.151 & 10.19 & 8.113 & 13.91 & -2.752 & 22.75 & & \\
\hline \multirow[t]{2}{*}{ wheatc } & 0.785 & 0.235 & 0.526 & 0.670 & -0.383 & 1.591 & 2.064 & 2.061 \\
\hline & 4.331 & 6.732 & 5.958 & 7.911 & -1.785 & 14.88 & & \\
\hline \multirow[t]{2}{*}{ wheatk } & 0.180 & 0.212 & 0.238 & 0.355 & -0.346 & 2.024 & 1.685 & 1.682 \\
\hline & 1.875 & 6.443 & 1.103 & 1.674 & -3.389 & 17.29 & & \\
\hline \multirow[t]{2}{*}{ palm } & 1.058 & 0.443 & 0.088 & 0.428 & -0.053 & 1.962 & 1.836 & 1.834 \\
\hline & 1.883 & 9.618 & 1.094 & 4.027 & -1.471 & 23.26 & & \\
\hline \multirow[t]{2}{*}{ rubber } & 1.058 & 0.310 & 0.492 & 0.604 & -0.038 & 2.034 & 1.678 & 1.676 \\
\hline & 2.161 & 5.355 & 2.255 & 2.761 & -0.595 & 15.82 & & \\
\hline
\end{tabular}

Notes: (1) The two entries for each parameter are their respective parameter estimates and robust $t$ - ratios. (2) Entries in bold are significant at the $5 \%$ level. 
Figure 1. Logarithm of Daily Agricultural Commodity Futures Returns
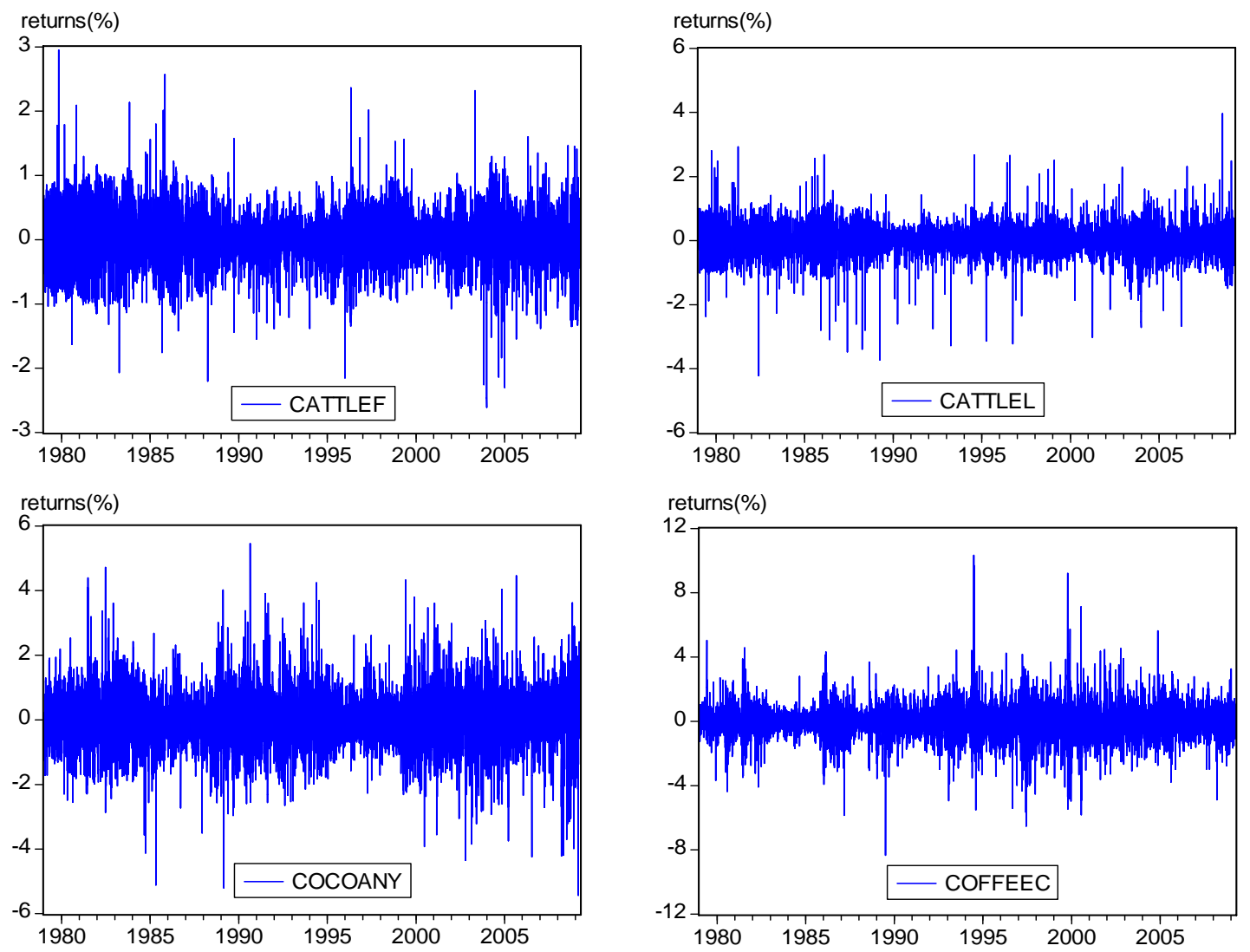

returns(\%)
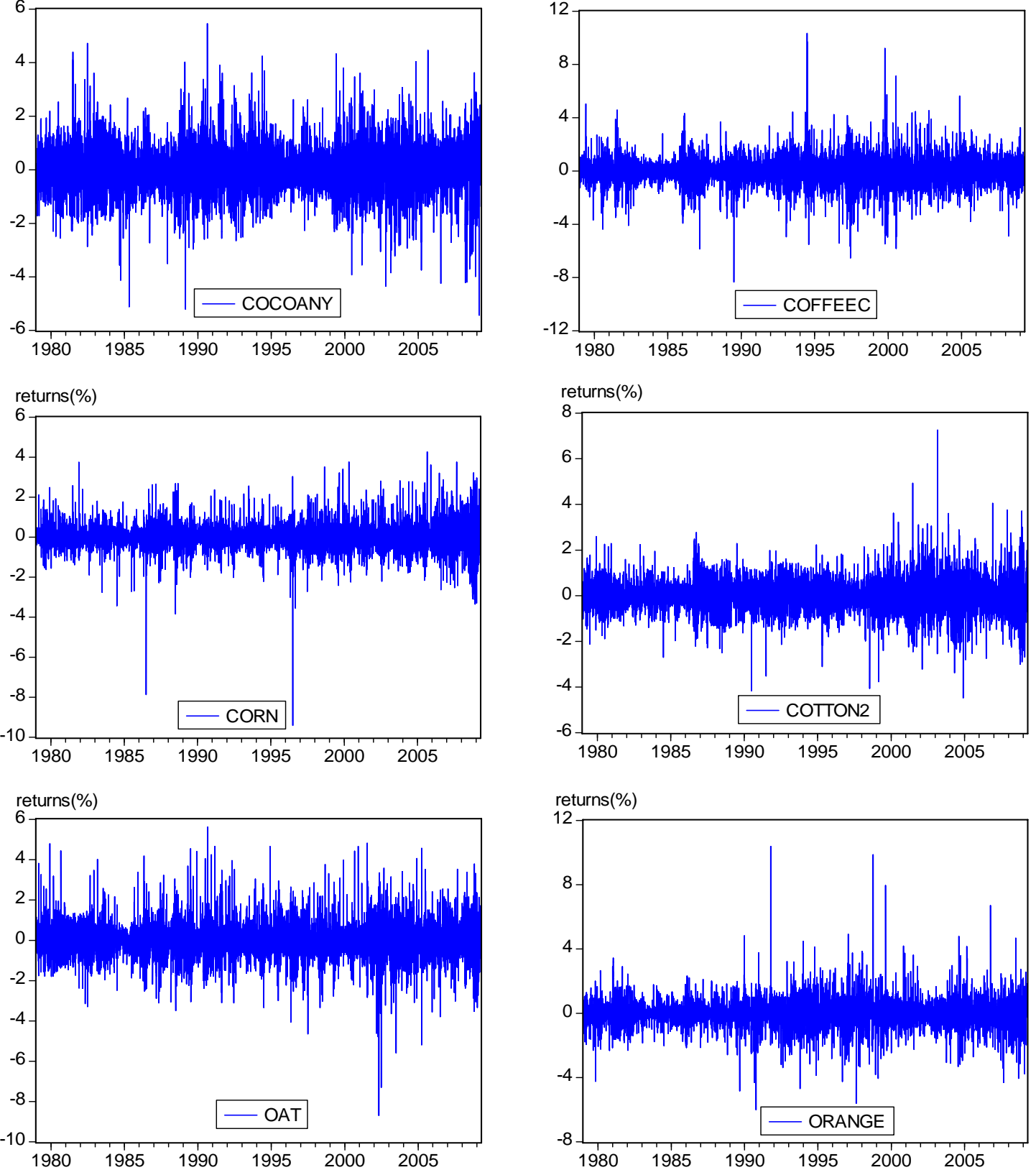
Figure 2. Logarithm of Daily Agricultural Commodity Futures Returns
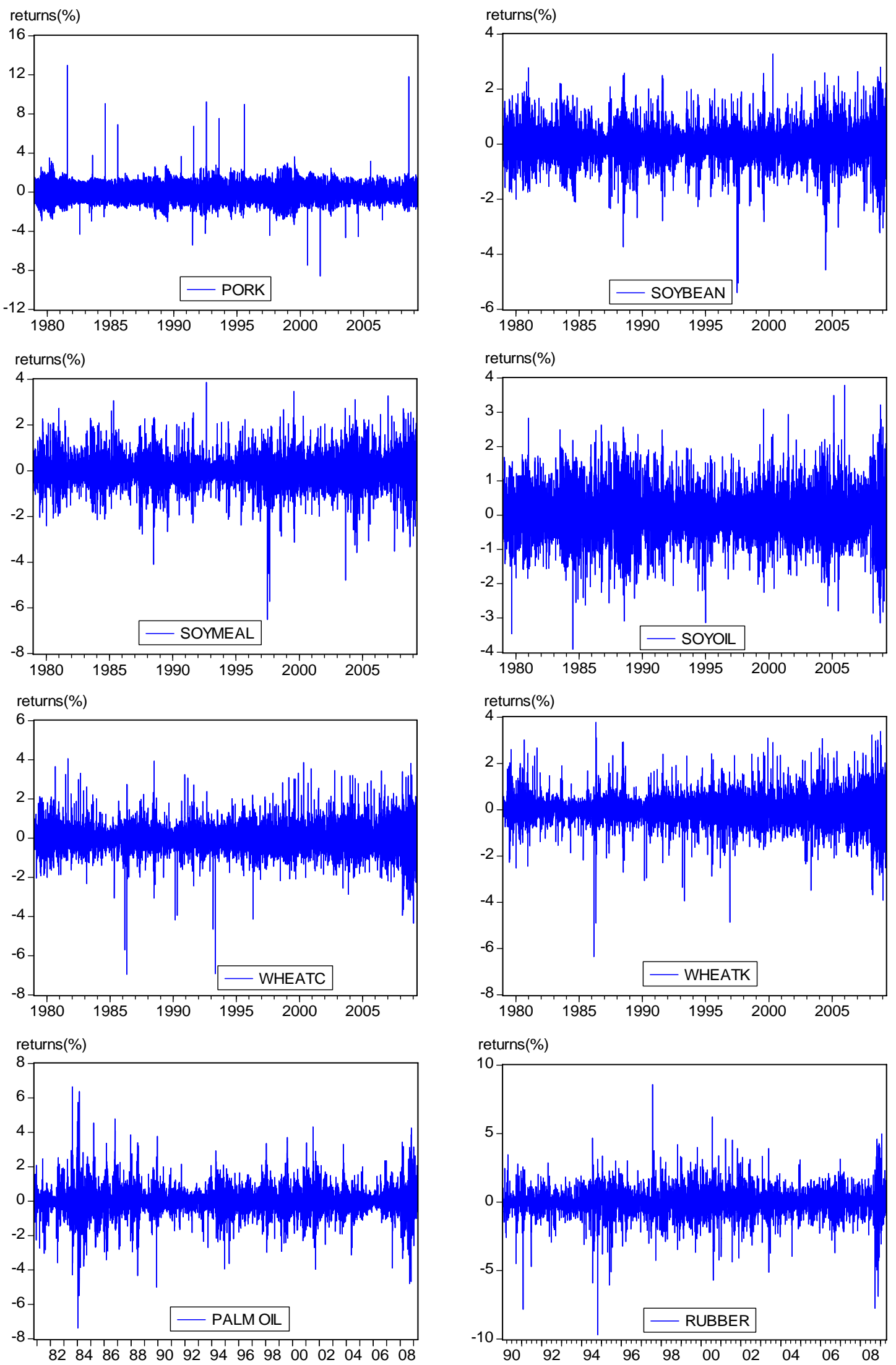